\title{
FABRICATION OF A SIMPLE MATERIALS SYSTEM FOR STUDY OF Hg IN A STAINLESS STEEL*
}

\author{
C. W. Allen, A. W. McCormick, B. J. Kestel,
}

P. M. Baldo, N. J. Zaluzec, and L. E. Rehn

Materials Science Division

Argonne National Laboratory

9700 S. Cass Ave.

Argonne, IL 60439

\section{November 1998}

The submitted manuscript has
been created by the University of
Chicago as Operator of Argonne
National Laboratory ("Argonne")
under Contract No. W-31-109-
ENG-38 with the U.S. Department
of Energy. The U.S. Government
retains for itself, and others
acting on its behalf, a paid-up,
non exclusive, irrevocable
worldwide license in said article
to reproduce, prepare derivative
works, distribute copies to the
public, and perform publicly and
display publicly, by or on behalt
of the Government.

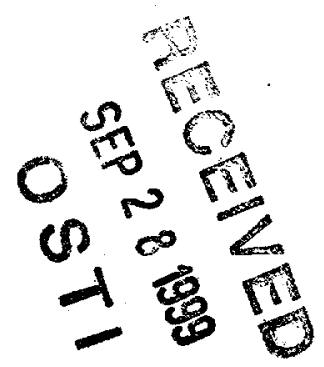

Submitted to the Materials Research Society, November 30 - December 4, 1998, Boston, MA.

*Work supported by the U. S. Department of Energy, Office of Basic Energy Sciences, under Contract W-31-109-Eng-38 at Argonne National Laboratory. 


\section{DISCLAIMER}

This report was prepared as an account of work sponsored by an agency of the United States Government. Neither the United States Government nor any agency thereof, nor any of their employees, make any warranty, express or implied, or assumes any legal liability or responsibility for the accuracy, completeness, or usefulness of any information, apparatus, product, or process disclosed, or represents that its use would not infringe privately owned rights. Reference herein to any specific commercial product, process, or service by trade name, trademark, manufacturer, or otherwise does not necessarily constitute or imply its endorsement, recommendation, or favoring by the United States Government or any agency thereof. The views and opinions of authors expressed herein do not necessarily state or reflect those of the United States Government or any agency thereof. 


\section{DISCLAIMER}

Portions of this document may be illegible in electronic image products. Images are produced from the best available original document. 


\section{FABRICATION OF A SIMPLE MATERIALS SYSTEM FOR STUDY OF $\mathrm{Hg}$ IN A STAINLESS STEEL*}

CHARLES W. ALLEN, ANTHONY W. MCCORMICK, BERNARD J. KESTEL, PETER M. BALDO, NESTOR J. ZALUZEC AND LYNN E. REHN

Materials Science Division, Argonne National Laboratory, Argonne, IL 60439

\section{ABSTRACT}

The Spallation Neutron Source (SNS), currently under construction at Oak Ridge National Laboratory, is expected to employ a $\mathrm{Hg}$ target encased in a stainless steel. Little is known about the metallurgical behavior of this materials engineering system, which will occur in a service environment involving elevated temperatures and intense radiation. Under normal equilibrium conditions, however, $\mathrm{Hg}$ is known to be insoluble in and non-reactive with solid $\mathrm{Fe}$ and $\mathrm{Cr}$ but to form one or more intermetallics with $\mathrm{Ni}$. $\mathrm{Hg}$ has been implanted into alloy 304L. For implantations at 400 and $500^{\circ} \mathrm{C}$ to a fluence of $3 \times 10^{16} \mathrm{~cm}^{-2}$ sub-micron sized precipitates of $\mathrm{Hg}$ are formed, as judged, for example, from their solidification behavior on cooling during TEM observation. The formation of such a system of microtargets and possible studies employing them as in situ TEM specimens are discussed, which can provide useful empirical information in conjunction with SNS target development.

\section{INTRODUCTION}

The Spallation Neutron Source (SNS) currently under construction at Oak Ridge National Laboratory will generate neutrons via spallation from an approximately $1 \mathrm{~mA}$ beam (pulsed) of $1 \mathrm{GeV}$ protons impacting a liquid- $\mathrm{Hg}$ target encased in a stainless steel. The choice of the target is dictated primarily by the need to generate useful neutrons for scattering experiments, to remove the large ( 1 MW) heat load generated, and to ensure that the target can withstand the high radiation environment (dpa, $\mathrm{H}$ and $\mathrm{He}$ generation) for reasonably long time periods (4-6 months). A liquid target was chosen because the dpa and gas production rates in a solid container for a liquid target are lower than those in the peak damage region of a solid target, and whereas the solid target material must be selected primarily for its neutron production characteristics, the material for containing a liquid can be selected primarily for its structural properties, including radiation damage resistance.

The uniqueness, complexity and high cost of the SNS target obviously complicate the need to determine its response to radiation damage. Although benchmark experiments involving irradiation of stainless-steel capsules containing liquid mercury are currently planned for a variety of different irradiation environments, such experiments require long times, and offer no chance to probe reasonably large areas of parameter space. In order to overcome these limitations, we have developed a simple materials system for investigating the irradiation response of liquid mercurycontaining stainless steel capsules. Large numbers of submicron precipitates of mercury (solid, liquid or gaseous) are generated by ion implantation into stainless steel at elevated temperatures. TEM specimens of this material can then be used in the HVEM-Tandem Facility for in situ irradiation effects studies here at Argonne to establish the response of the encapsulated $\mathrm{Hg}$ and its container material to a wide variety of irradiation conditions, including dpa rates, and $\mathrm{H}$ - and He-generation rates,

* Work supported by the U. S. Department of Energy, BES-Materials Sciences, under Contract W-31-109-Eng-38. 
far in excess of those anticipated for the SNS target.

In this paper, we report the first successful results from this development. We show that the extremely low solubility of $\mathrm{Hg}$ in stainless steels results in submicron precipitates of $\mathrm{Hg}$ following its implantation into a $304 \mathrm{~L}$ stainless steel at elevated temperatures. In situ microscopy experiments as a function of temperature between -220 and $+400{ }^{\circ} \mathrm{C}$ reveal that the melting and boiling points of the encapsulated $\mathrm{Hg}$ lie within experimental error of those for pure $\mathrm{Hg}$ at atmospheric pressure. Since the precipitates are formed in the gaseous state, thermodynamic parameters ensure that when the $\mathrm{Hg}$ liquifies upon cooling, it is contained in this nearly equilibrium (i.e. unpressurized) state.

\section{SPECIMEN PREPARATION AND QUALITY}

Well annealed $3 \mathrm{~mm}$ discs of commercial AISI Type $304 \mathrm{~L}$ stainless steel approximately $100 \mu \mathrm{m}$ thick were prepared for $\mathrm{Hg}$ implantation and subsequent TEM foil preparation. The discs were implanted with $500 \mathrm{keV} \mathrm{Hg}$ at 400 and $500{ }^{\circ} \mathrm{C}$ to a typical fluence of $2-3 \times 10^{16} \mathrm{~cm}^{-2}$. The source starting material was $\mathrm{HgS}$ in a Type 911 source. The post-implanted discs were back-thinned by single jet electropolishing with an electrolyte consisting of $50 \mathrm{ml}$ perchloric acid, $450 \mathrm{ml}$ acetic acid and $50 \mathrm{ml}$ butylcellosolve at a temperature of $20^{\circ} \mathrm{C}$ and potential of $42.5 \mathrm{~V}$. Early attempts to implant TEM foils of $304 \mathrm{~L}$ in situ in an Hitachi H-9000NAR with ion beamline interface in the HVEM-Tandem Facility at Argonne [1, 2] were abandoned because of the large $\mathrm{Hg}$-induced sputtering rate of the matrix material. Several room temperature implantations were also attempted but subsequent TEM failed to reveal evidence of $\mathrm{Hg}$ precipitation.

In order to verify the presence of $\mathrm{Hg}$ in precipitates in the as-implanted material, X-ray energy dispersive spectroscopy (XEDS) of an as-implanted stainless steel TEM specimen was performed in the Vacuum Generators VG-603, an ultrahigh vacuum TEM/STEM with cold field emission electron source. XEDS spectra were acquired for an acquisition time of $100 \mathrm{~s}$. Fig. 1 shows spectra from the same area with the central $\mathrm{Hg}$ precipitate before and shortly after the fine electron probe had drilled a hole through the specimen, allowing the $\mathrm{Hg}$ to escape from the matrix cavity. This also demonstrates that the $\mathrm{Hg}$ precipitates are inside the foil, not on the surface.

\section{THERMAL BEHAVIOR OF AS-IMPLANTED Hg IN 304L}

Several additional tests were performed to verify that the implanted precipitates were indeed $\mathrm{Hg}$. These tests included heating and cooling between ambient temperature and $500^{\circ} \mathrm{C}$ to examine differential thermal expansion behavior and cooling and heating between ambient temperature and $-180^{\circ} \mathrm{C}$ to examine freezing and melting behavior of the precipitates. These experiments were performed in situ in the Hitachi H-9000NAR, an intermediate voltage TEM known as the IVEM. The elevated temperature observations employed a Gatan double tilt, water-cooled heating holder. For the low tempertature experiments an Oxford double tilt, heliumgas cooled holder was employed.

\section{Differential thermal expansion behavior}

The volume thermal expansion coefficient $\alpha_{V}$ is more than three times larger for liquid $\mathrm{Hg}$ than for $304 \mathrm{~L}$ stainless steel over the entire temperature range for liquid $\mathrm{Hg}\left(\alpha_{\mathrm{L}}[304 \mathrm{~L}]=18 \times 10^{-6}{ }^{\circ} \mathrm{K}^{-1}\right.$ and $\left.\alpha_{\mathrm{L}}[\mathrm{Liq} . \mathrm{Hg}]=60 \times 10^{-6}{ }^{\circ} \mathrm{K}^{-1}\right)$. Following implantation 
of $\mathrm{Hg}$ at $500^{\circ} \mathrm{C}$, a shrinkage cavity (void) appears in the $\mathrm{Hg}$ precipitates on cooling of the implanted material in the temperature range at which liquid and vapor are in equilibrium (the boiling point of $\mathrm{Hg}$ at $1 \mathrm{~atm}$ is about $630 \mathrm{~K}$; in the absence of voids in the $\mathrm{Hg}$, the surface tension of $\mathrm{Hg}$ /matrix interfaces may constrain the $\mathrm{Hg}$ in the liquid state above $630 \mathrm{~K}$, the boiling point increasing on the order of $10^{\circ} \mathrm{K} / \mathrm{MPa}$ [3]). Such a shrinkage cavity becomes larger as temperature is decreased. TEM imaging of these voids depends on several factors relating to the contrast of the precipitates and matrix. Fig. 2 shows a series of bright field TEM images obtained during a heating experiment of an implanted foil, showing the motion and change in diameter of voids in several $\mathrm{Hg}$ precipitates at approximately (a) 27, (b) 150 , (c) 350 and (d) $400^{\circ} \mathrm{C}$.

\section{Freezing and melting behavior}

Cooling followed by warming experiments were also conducted to examine the behavior of the $\mathrm{Hg}$ precipitates as a function of temperature. In order to avoid possible effects of undercooling, tests were performed on warming from low temperatures. On warming, in principle six characteristics of the $\mathrm{Hg}$ precipitates may be employed as indicators of the solid-liquid transition: the disappearance of matrixprecipitate moiré fringes, the change in precipitate diffraction contrast, disappearance of precipitate reflections from a diffraction pattern, the disappearance of faceting of voids inside precipitates, an abrupt decrease of void size associated with expansion of $\mathrm{Hg}$ on melting ( $3.6 \mathrm{pct})$ and the onset of movement of voids inside precipitates. Especially for fine precipitates, it is difficult to pinpoint the transition temperature with great precision by any of these, however [4]. Figs. 3(a) and (b) illustrate the normal dependence of moiré fringes and precipitate contrast on specimen orientation. Figs. 3(c) and (d) illustrate the disappearance of moire fringes for two of the four fringed precipitates as the specimen is slowly heated from 202 to $206 \mathrm{~K}$. This demonstrates the sensitivity of this type of observation to the matrix and precipitate orientations, changing only very slightly locally in this case with temperature. Thus while this is a good method for estimation of the transition temperature in principle, one must assure that the disappearance of the moire fringes or other changes in contrast are not due to a subtle orientation changed in the field of observation. Presumeably because of thickness and short wavelength orientation differences of the matrix, selected area diffraction patterns clearly indicating the presence of crystalline $\mathrm{Hg}$ could not be obtained. Thus we have insufficient data for illustration of these methods at this point.

Fig. 4 illustrates the behavior of void faceting and motion at (a) 25, (b) 150, (c) 200 and (d) $225 \mathrm{~K}$. In this particular example faceting of the voids is clearly present at $200 \mathrm{~K}$ (though not so pronounced as at lower temperatures) and is absent at $225 \mathrm{~K}$. Because faceting to nonfaceting transitions are known for precipitates in the solid state, this imay not be a very reliable indicator of the transition to liquid. In addition the voids in precipitates $D$ and $E$ have moved between Figs. $4(\mathrm{c})$ and (d). The onset of void motion is observed to be highly variable, however, as is the motion itself. Even at ambient temperature under constant TEM observation conditions the void in a given precipitate may sit motionless for long periods of time, then move about for some minutes before stopping again, as if the void were at a metastable position on the precitate/matrix interface until sufficiently stimulated to migrate and eventually settle into another metastable position somewhere on the interface.

The final potential indicator of melting is the abrupt shrinkage of voids inside precipitates on melting of the $\mathrm{Hg}$. The less than 4 pct decrease in density of $\mathrm{Hg}$ on melting is difficult to pick up by eye during the warming process; however, close 
examination of video recordings of images over this period, correlated with temperature indications and other commentary recorded on the audio track, make this considerably more reliable.

The standard melting and triple points of $\mathrm{Hg}$ are about $-38.8^{\circ} \mathrm{C}$. Estimates from the several indicators described above are lower than this by amounts varying from $9-32{ }^{\circ} \mathrm{C}$. The $9{ }^{\circ} \mathrm{C}$ discrepancy may be due to inaccuracy of the temperature readout of the specimen holder. In any event, the $\mathrm{Hg}$ precipitates are solid at indicated temperatures of $-48^{\circ} \mathrm{C}$ and liquid at $-30^{\circ} \mathrm{C}$.

\section{IN SITU EXPERIMENTS EMPLOYING Hg MICROTARGETS}

The behavior of $\mathrm{Hg}$ in irradiation environments is of considerable concern in regard to its application as a spallation neutron source. We suggest that the methods of in situ TEM with ion and/or electron irradiation as experimental parameters provide a fruitful and temporally efficient means of exploring an important section of parameter space in relation to irradiation-induced phenomena and effects associated with implantation of gases such as $\mathrm{He}$.

In its simplest form, one possible area of interest concerns the metallurgical behavior of the quartenary system $\mathrm{Fe}-\mathrm{Cr}-\mathrm{Ni}-\mathrm{Hg}$. The equilibrium ternary $\mathrm{Fe}-\mathrm{Cr}-\mathrm{Ni}$ system and binary $\mathrm{Fe}-\mathrm{Hg}, \mathrm{Cr}-\mathrm{Hg}$ and $\mathrm{Ni}-\mathrm{Hg}$ systems are reasonably well established. Employing the $\mathrm{Hg}$ microtargets in a particular stainless steel, one may examine the effects of displacing irradiation on possible reactions involving the alloy system components. With respect to the binary systems involving $\mathrm{Hg}$ with $\mathrm{Fe}, \mathrm{Cr}$ and $\mathrm{Ni}$, the solubility limits of $\mathrm{Fe}, \mathrm{Cr}$ and $\mathrm{Ni}$ in $\mathrm{Hg}$ are practically zero for temperatures at least as high as $500^{\circ} \mathrm{C}$ (e.g., at $500^{\circ} \mathrm{C}$, the solubility of $\mathrm{Fe}$ in $\mathrm{Hg}$ is of the order $10^{-4}$ at. pct. [5]). At lower temperatures the formation of intermetallics is restricted to the $\mathrm{Hg}-\mathrm{Ni}$ system with the formation of $\mathrm{Hg}_{4} \mathrm{Ni}$ by peritectic reaction at about $250^{\circ} \mathrm{C}$ and the peritectoid reaction of $\mathrm{Hg}_{4} \mathrm{Ni}$ and $\mathrm{Ni}$ to form $\mathrm{HgNi}$ at about $110^{\circ} \mathrm{C}$. If either of these reactions were to proceed in a $\mathrm{Hg}$-austenitic stainless steel system, one would predict local depletion of $\mathrm{Ni}$, possibly moving the composition of the stainless steel locally from austenitic to ferritic/martensitic. While one does not expect significant wetting of austenite grain boundaries by $\mathrm{Hg}$, depletion of $\mathrm{Cr}$ at austenite boundaries and surfaces by radiation-induced segregation would lead to an enhanced $\mathrm{Ni}$ concentration there, so that the reaction of $\mathrm{Hg}$ and $\mathrm{Ni}$ might be enhanced at these sites at operating temperatures below $250^{\circ} \mathrm{C}$.

A second type of in situ experiment involves the behavior of implanted gases such as $\mathrm{He}$ and $\mathrm{H}$ on the response of microtargets to subsequent ion irradiation damage. The microtarget material described earlier in this presentation would serve as an ideal material system for investigation of such questions by means of TEM with in situ irradiation capability. The HVEM-Tandem Facility at Argonne is very well suited for such studies.

\section{ACKNOWLEDGMENTS}

The authors acknowledge with gratitude the assistance of $E$. A. Ryan for his assisitance with the low temperature experiments and of R. C. Birtcher for many helpful discussions. 


\section{REFERENCES}

[1] C. W. Allen, L. L. Funk, and E. A. Ryan, Mat. Res. Soc. Symp. Proc. 396 (1996) 641-646.

[2] C. W. Allen and E. A. Ryan, Mat. Res. Soc. Symp. Proc. 439 (1997) 277-287.

[3] D. Ambrose and C. H. S. Sprake, J. Chem. Thermodyn., 4 (1972) 603-620.

[4] For example, H. Saka, Y. Nishikawa and T. Imura, Phil. Mag. A 57 (1988) 895906.

[5] A. L. Marshall, L. F. Epstein and F. J. Norton, J. Am. Chem. Soc., 72 (1950) 3514-3516.

\section{FIGURE CAPTIONS}

FIG. 1. X-ray energy dispersive spectroscopy of a Hg precipitate at $300 \mathrm{~K}$ within 304 $L$ stainless steel matrix, employing fine $300 \mathrm{kV}$ electron probe, (lefthand portion of figure) and of the same region after the elecron probe has sputtered a hole into the precipitate, causing the $\mathrm{Hg}$ to escape (righthand portion of the figure).

FIG. 2. Bright field TEM images of $\mathrm{Hg}$ preciitates in $304 \mathrm{~L}$ stainless steel, produced by ion implantation at $500^{\circ} \mathrm{C}$ to a fluence of $3 \times 10^{16} \mathrm{~cm}^{-2}$ followed by cooling to room temperature. (a) $27^{\circ} \mathrm{C}$. (b) $150^{\circ} \mathrm{C}$. (c) $350^{\circ} \mathrm{C}$. (d) $400^{\circ} \mathrm{C}$.

FIG. 3. Effect of small specimen tilts on bright field TEM images of $\mathrm{Hg}$ preciitates in $304 \mathrm{~L}$ stainless steel, produced by ion implantation at $500{ }^{\circ} \mathrm{C}$ to a fluence of $3 \times 10^{16} \mathrm{~cm}^{-2}$ followed by cooling to room temperature and subsequently to $97 \mathrm{~K}$. (a) $97 \mathrm{~K} ;-6.1^{\circ}$ specimen holder tilt. (b) $100 \mathrm{~K} ;-9.1^{\circ}$ specimen holder tilt. (c) 202 $\mathrm{K} ;-5.9^{\circ}$ specimen holder tilt. (d) $206 \mathrm{~K} ;-5.9$ specimen holder tilt.

FIG. 4. Effect of warming from $25 \mathrm{~K}$ on bright field TEM images of $\mathrm{Hg}$ preciitates with voids in $304 \mathrm{~L}$ stainless steel, produced by ion implantation at $500{ }^{\circ} \mathrm{C}$ to a fluence of $3 \times 10^{16} \mathrm{~cm}^{-2}$ followed by cooling to room temperature and subsequent cooling to $25 \mathrm{~K}$. (a) $25 \mathrm{~K}$. (b) $152 \mathrm{~K}$. (c) $200 \mathrm{~K}$. (d) $226 \mathrm{~K}$. 

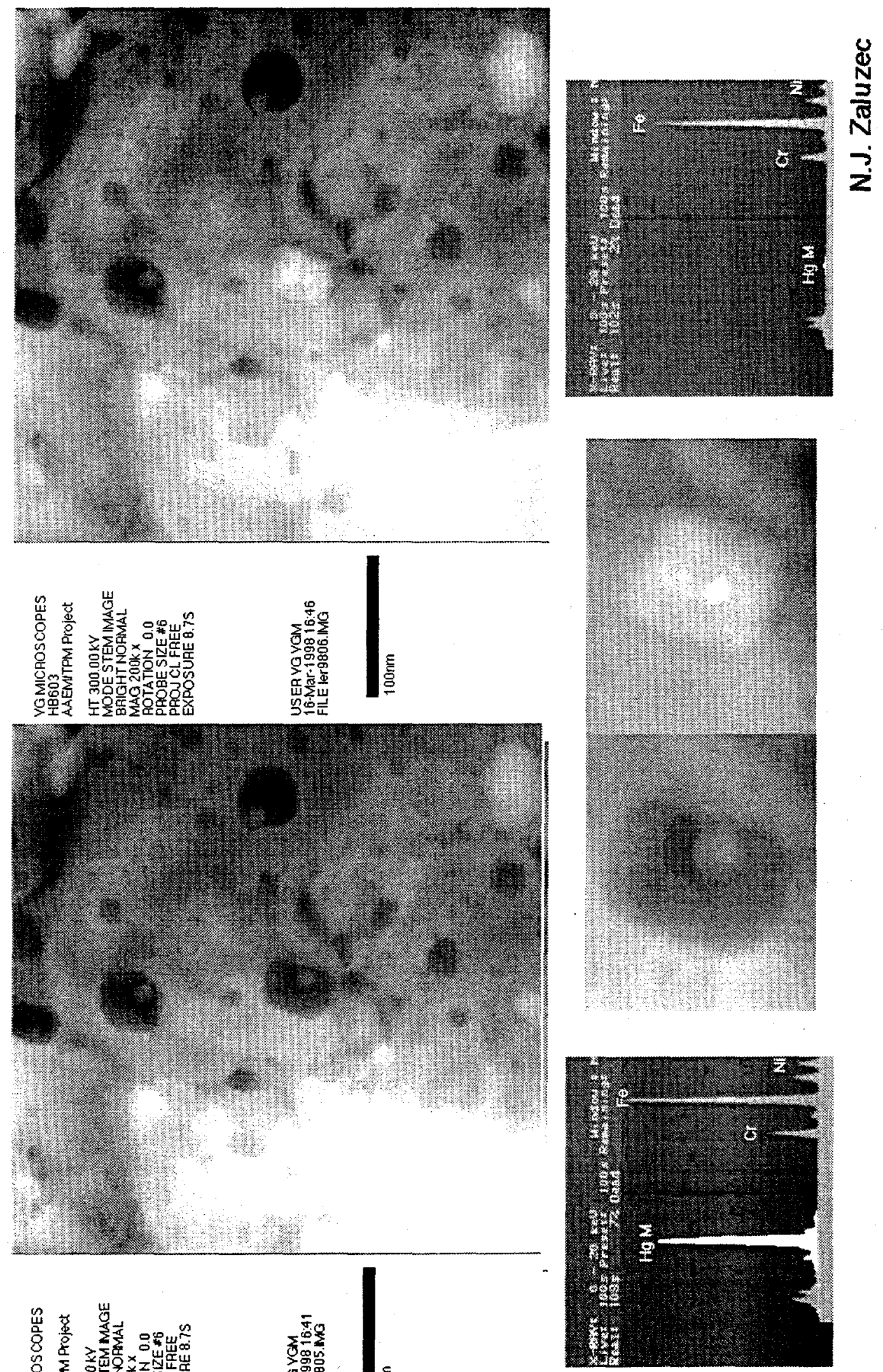

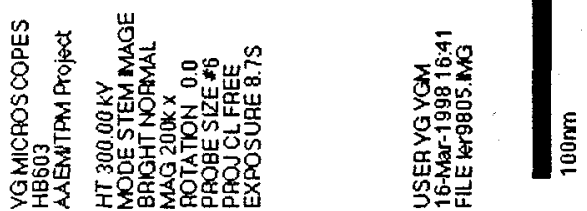

FI6. 

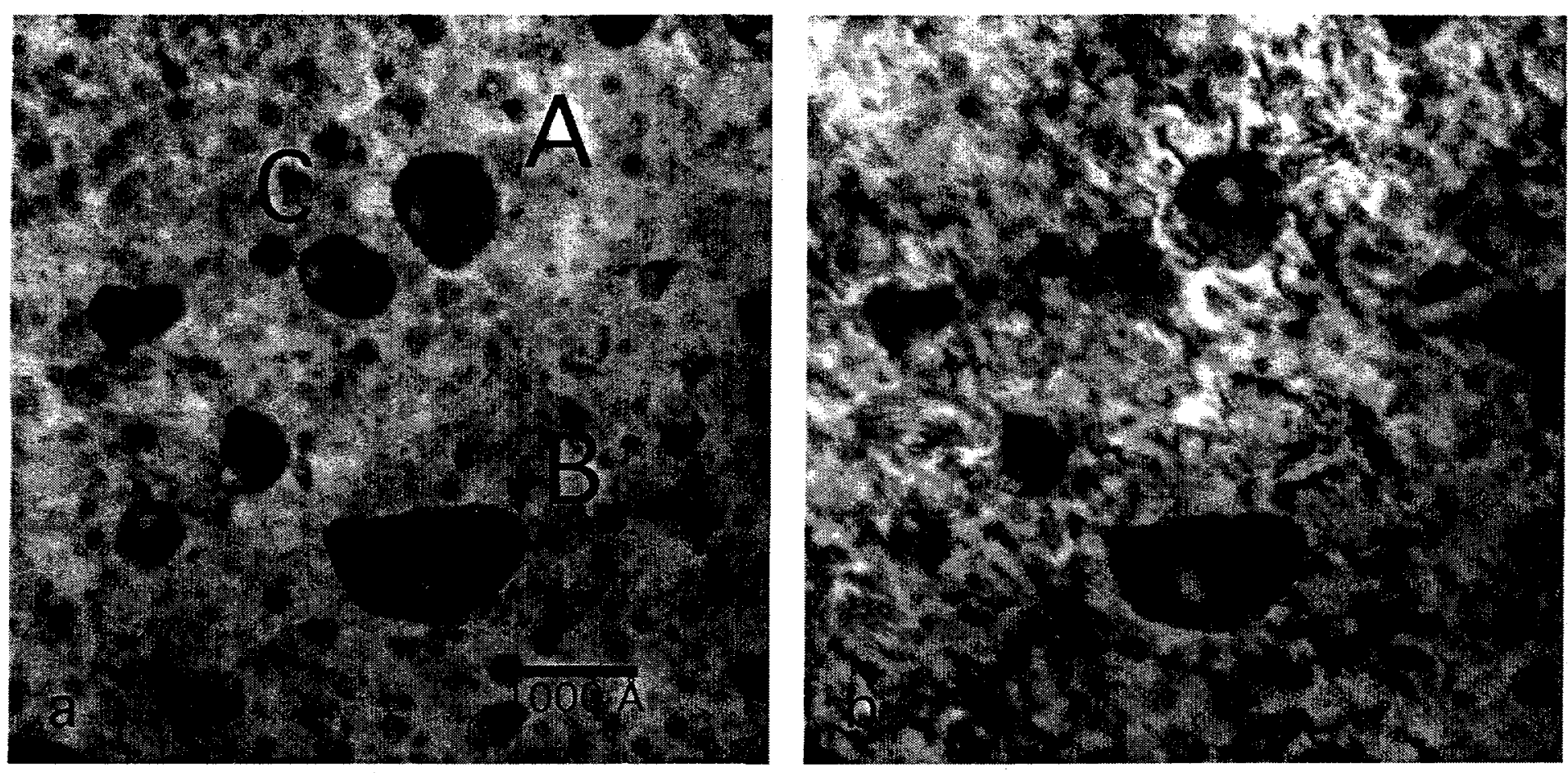

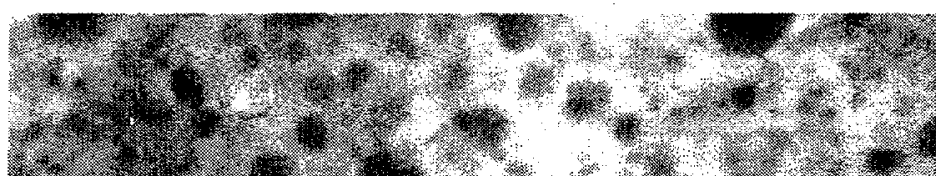

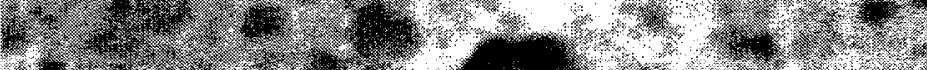

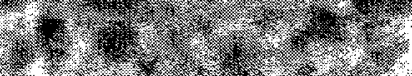
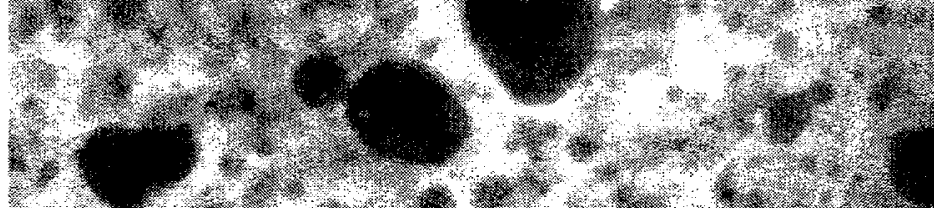

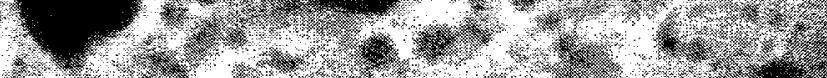
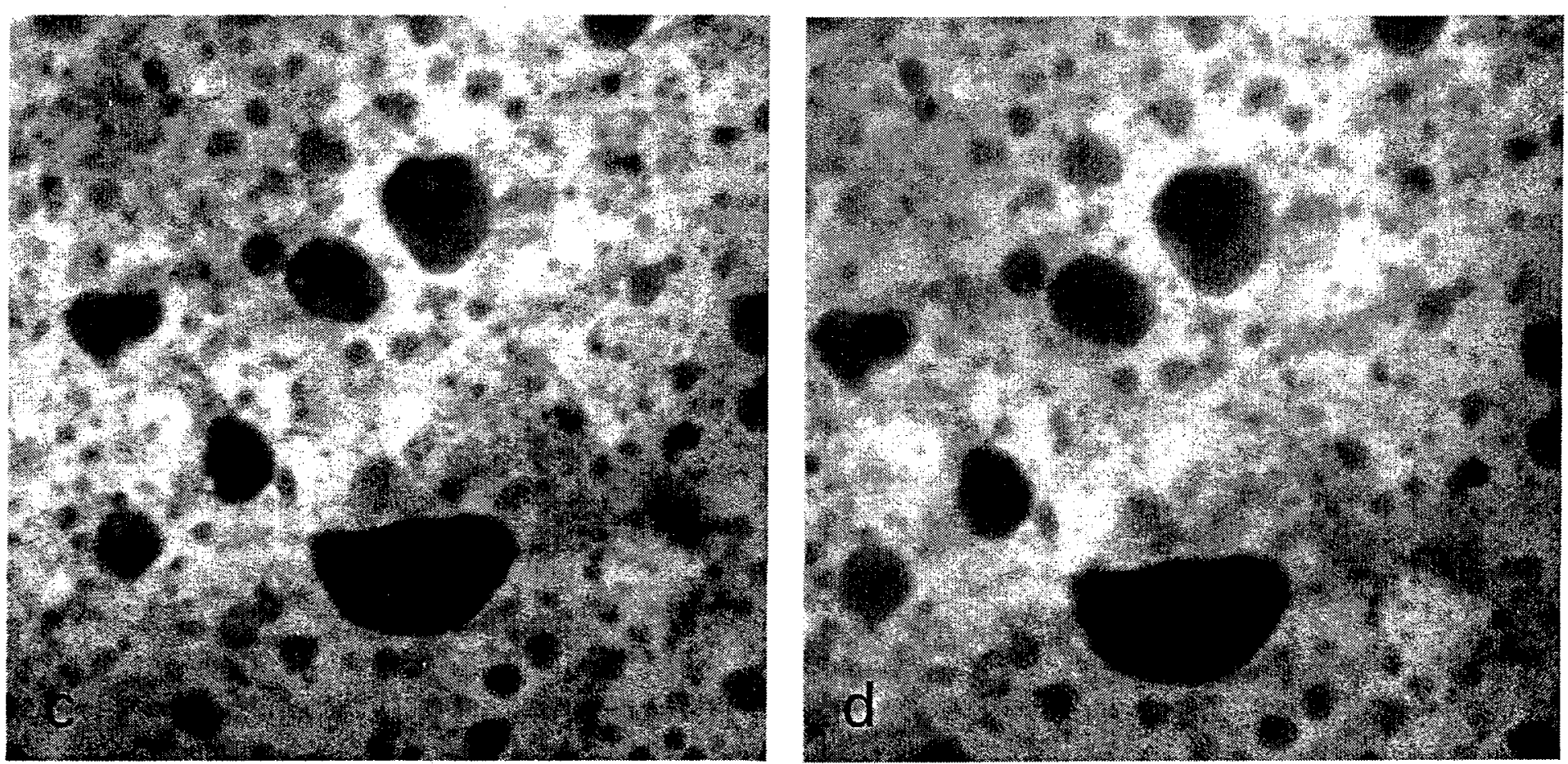

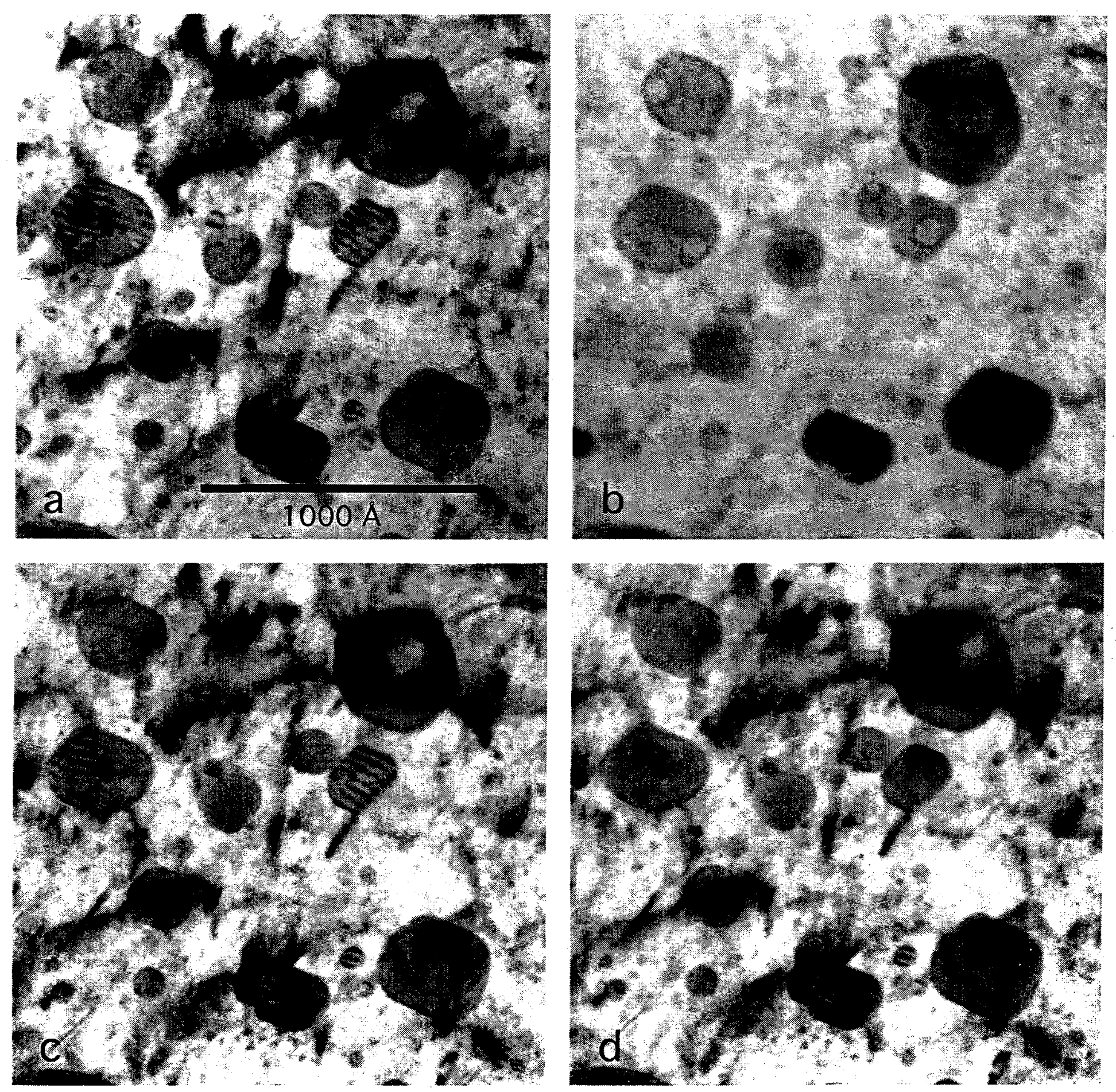

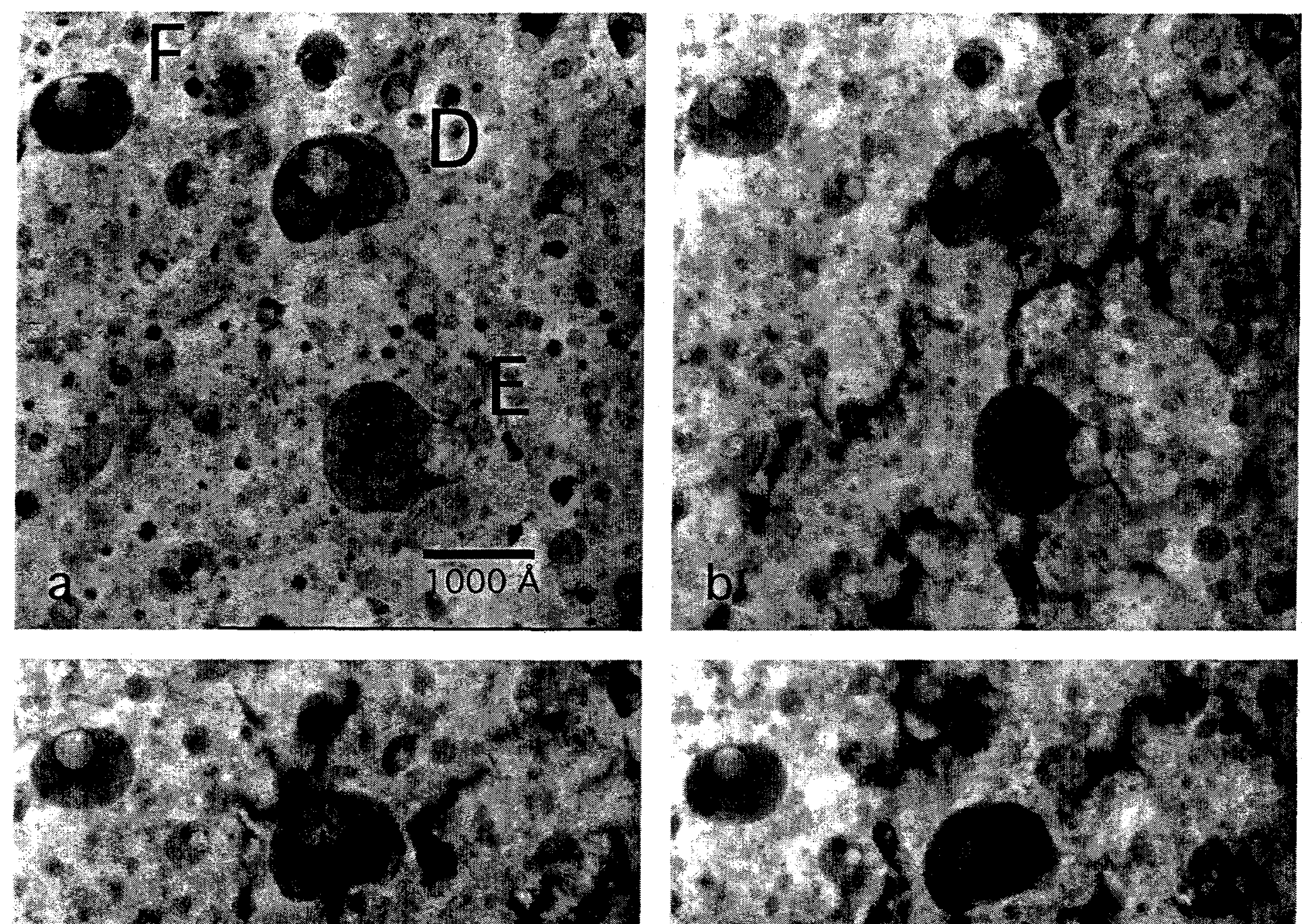

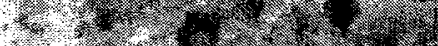

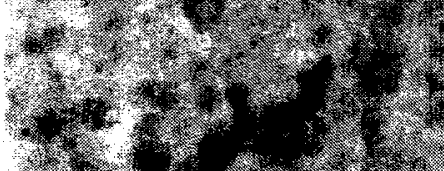

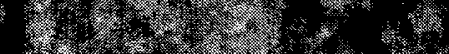

; P.

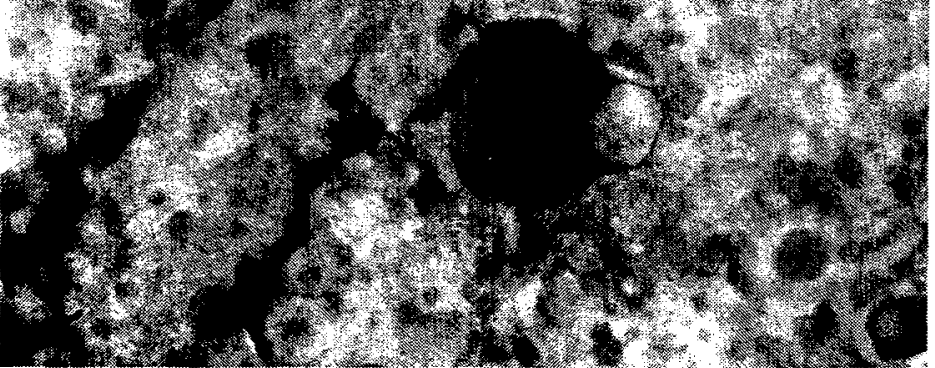

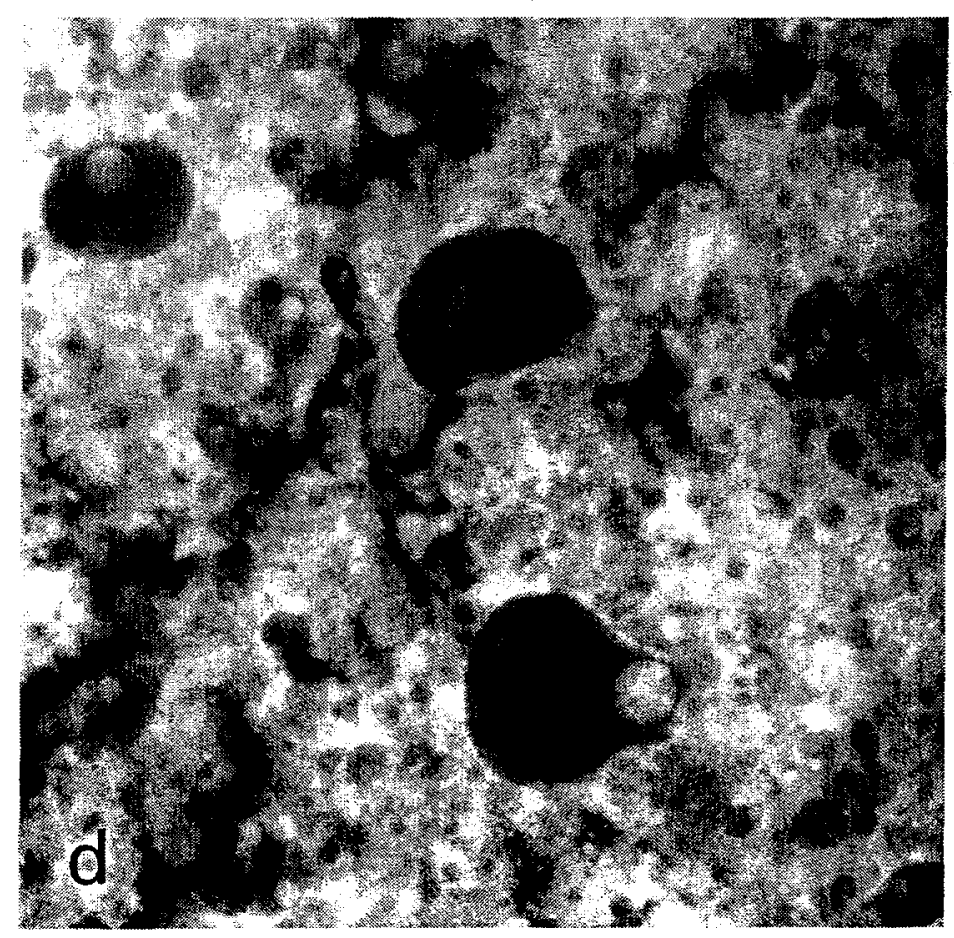

